\title{
Review of Online Discussion Board to Improve Academic Achievement in Pandemic Time Learning
}

\section{Sudarmo}

Sekolah Tinggi Ilmu Ekonomi Balikpapan, Indonesia

sudarmo@stiebalikpapan.ac.id

\begin{tabular}{|c|c|}
\hline & Abstract \\
\hline & $\begin{array}{l}\text { This article analyzed online board discussions' effectiveness as an alternative } \\
\text { learning method in response to health protocol policies and compulsory } \\
\text { education during Indonesia's pandemic emergency. Since COVID-19 hit in the }\end{array}$ \\
\hline $\begin{array}{l}\text { ARTICLE INFO } \\
\text { Article history: }\end{array}$ & $\begin{array}{l}\text { world, WHO and UNESCO have obliged all countries has been applying } \\
\text { technology-assisted distance learning. To get the learning application's }\end{array}$ \\
\hline Received & effectiveness using the online discussion board method. The researcher analyzed \\
\hline $\begin{array}{l}\text { November 16, } \\
2020\end{array}$ & $\begin{array}{l}\text { fifteen findings of learning experts during the pandemic, which were published } \\
\text { in international journals. The researcher analyzed qualitatively through coding, }\end{array}$ \\
\hline Revised & in-depth interpretation and concluding and ensures that the findings were valid \\
\hline $\begin{array}{l}\text { November } 22 \text {, } \\
\quad 2020\end{array}$ & $\begin{array}{l}\text { and reliable. The results showed that the online discussion board has become an } \\
\text { alternative method during learning during the COVID-19 period, such as podcast }\end{array}$ \\
\hline Accepted & applications, ZOOM, Google Classroom. Therefore, the researcher recommends \\
\hline December 2, 2020 & $\begin{array}{l}\text { that applying this online discussion as most method was recommended to } \\
\text { improve learning and maintain safety during a pandemic. }\end{array}$ \\
\hline
\end{tabular}

Published by

Keywords: Online Discussion Board, Improving Academic Achievement, Learning in Pandemic

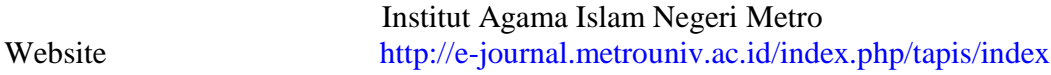

This is an open access article under the CC BY SA license

https://creativecommons.org/licenses/by-sa/4.0/

\section{INTRODUCTION}

Since the coronavirus 2019 (COVID-19) hit the world, the global institution in the health sector of WHO, education, and UNESCO culture has obliged every country to adopt a healthy way of life, avoiding the threat of COVID-19 transmission. (Crawford et al., 2020; Putra et al., 2020). Hence, all business activities and life outside the home have stopped, and including educational activities are pursued using a distance method with technological facilities and media. Work and study from home should be a worldwide solution and trend. Apart from the various problems caused, the online learning system has to be implemented to take still the education that is usually obtained in the schoolroom using face-to-face learning methods and gather in one school building complex (Ilyasa et al., 2020; Surani, \& Hamidah, 2020). Therefore, to anticipate the situation, learning to rely on internet technology and networks is a new thing. Students can now access course materials quickly and even for free from online learning apps and sites (Fauzi et al., 2020). One application that is very easy and very helpful for distance learning success is the online discussion board method both in writing and orally, which gives different nuances; connect learning resources (teachers) with students online.

Online discussion boards are believed to help create the presence of online social learning together in the air with a sense of togetherness and reduce embarrassment and embarrassment, such as in face-to-face classes. The presence of social nuances with other communities at a distance, in turn, can increase a sense of emotional connection and real attachment between

Doi

http://dx.doi.org/10.32332/tapis.v3i2.2595

ISSN Print 2579-3233; Online 2580-068X

| Volume 4 Number 2, December 2020, page 183-191 
network users. Thus they are either teachers or students who also enhance enjoyable learning and can create the same feeling that is more satisfied with the field that is their subject. The discussion board assignment's ultimate goal is to help participants or students communicate both written and oral methods with each other. However, the presenter or teacher is asked to continue to rethink their discussion board's use and effectiveness, which emphasizes that all participants play a communicative role that rarely occurs in face-to-face learning methods. Although some students may feel very embarrassed or reluctant to participate from an early age, online discussion instructors and presenters must actively teach everyone to be active and productive if they are involved in online discussion boards to improve learning achievement.

Discussion activities can create practical and efficient learning because this activity can also activate participant participation. The subject is not the object of teaching, as is usually the case in classroom learning programs. Ideally, students no need to come to class, but it is enough to use technology appropriately. This kind of activity can motivate students to have the ability to think and communicate in real situations, even over long distances. Apart from that, the participants also learn challenged to present their knowledge when they understand and respond to the topic and ensure that learning active process. Cheng et al., (2011) said that students who took part in discussion forums tended to have a better academic performance at school. They believe that by participating in online discussion boards, especially discussion activities for written posts on various application forums, their achievements increase. Many other studies provide empirical support for theoretical evidence that facilitates students' online discussion board forums on the average achievement of subjects. So other research also shows that the implementation of online discussion boards is beneficial even though the teachers can only spend a little time on this online discussion forum (Romero et al., 2013; Coetzee et al., 2014).

Several studies have produced critical studies that this kind of discussion approach can produce a substantial increase in reducing students' feelings of reluctance at the same time as talking to teachers. This online, while able to significantly increase learning outcomes in the real-world practice increasing the teacher's enthusiasm to create an increase in students' literal or inferential understanding, critical thinking, and sharp reasoning. Machado et al., (2020) said that the online discussion boards are also recommended for use in the classroom for teachers, especially with learning conditions during the pandemic era and other educational disruptions. In online classroom discussion boards, all participants can create learning such as with friends by creating a positive relationship. According to Jones et al., (1998) creating peer relationships affects student achievement. Several ways, including students, can behave with peers and excel in influencing fellow students' academic aspirations. Able to improve the quality of peer learning with peer-to-peer relationships and support in online classes. This method is able to influence the extent the needs of learners are met and, Furthermore, it is able to improve the participants' ability to become fully engaged in online board discussion learning. Another advantage is that creating peer relationships can directly affect learning outcomes through collaborative and fun learning activities. There are indeed several circumstances and criteria for having an excellent online discussion board to be there. This online discussion continue to run better and full academic achievement if they are creating multiple criteria. An exciting and supportive situation must be designed to achieve online discussion, which attracts all discussion participants. This trend is in line with the principle of transferring student responsibilities for online learning during the demise period; learning groups are increasingly applying online discussion boards. Regarding online discussions, Palloff \& Pratt, (2007) argue that promoting distance learning community participants requires an effective strategy to create virtual classrooms so they can explore the development of online learning environments that promote a sense of togetherness and invite students to be together are responsible for their learning to achieve optimal learning outcomes. Online discussion with all its advantages and conveniences has proven to be a very effective method of promoting learning achievement. (Caffarella \& Daffron, 2013; Daloz, 2012).

There are several reasons the author chose online discussion boards to improve learning outcomes during a pandemic. This densely populated techno-culture learning method can facilitate more effective and flexible online class discussion activities. This issue is an essential 
thing that is very fundamental to support student learning in times of the COVID-19 crisis with a straightforward method where helping each other is the most "communication" and effective means. Observations from daily online learning today are unmistakably visible to the world community. They collaborate with online technology with various applications that are very intimate and efficient, such as online discussion applications via the ZOOM platform, Google Classroom, Social Networking. According to their skills, these applications are the most natural and effective for online discussion participants in listening, responding, and speaking freely in the language. Online discussions motivate cooperative or collaborative learning and spontaneous thinking acuity, which familiarizes and prepares all students to learn and work in teams. This learning system is easily familiar among students studying during a pandemic. It is different from the offline learning system for board discussion, which was impossible during COVID-19 at this time. After all, face to face discussion is limited with classmates only. So the collaboration is unlimited, that the learning outcomes are still limited. However, to improve learning outcomes using online discussion boards, teachers and students can learn to have online discussions that are creative, highly motivational, and have the opportunity to collaborate between countries even when face to face was impossible (Lassoued et al., 2020).

This online discussion can also be an alternative technique for nurturing students to tell stories with other participants more confidently. When they are invited to express their thoughts, they usually feel temporarily unprepared because everything is in front of their eyes in scientific language academics. On this basis, the researcher chose online discussion method to increase academic achievement, and at the same time, they could avoid difficulties in expressing their goals. This researcher analyzed online board discussions' effectiveness as an alternative learning method in response to health protocol policies and compulsory education during Indonesia's pandemic emergency.

\section{METHOD}

The phenomenological approach was chosen as a practical method of collecting data, completing the analysis process, and reporting results. Smith and Osborn (2020) suggested that this method was used in many qualitative studies because its phenomenological nature can provide an overview of how to understand a person's experiences or events. That way, the researchers explored what the real purpose of the research being carried out. The researchers collected and selected ten international publications on teaching and learning based on technology applications in the COVID-19 learning era. Furthermore, data was analyzed qualitatively under a phenomenological approach by analyzing the coding process and in-depth interpretation. Based on scientific and empirical evidence, the researcher found the answer to this study's question with high validity and reliability (McMillan and Schumacher, 2010). The researcher explored what the real purpose of the research being carried out is. The researcher conducted a search for headlines of online newspapers and then a critical analysis of the content of these headlines (international scientific publications). In searching the data, the researcher conducted searching using a keywords; "online discussion board," "pandemic era learning," qualitative studies," "increasing learning achievement," "learning from home, "and" technologybased competence for learning. " Therefore, the researcher succeeded in an in-depth review of five teen international scientific publications with the theme that the online discussion board.

\section{RESULT AND DISCUSSION}

In the results section, this article described ten international publications on the effectiveness of using online discussion boards to improve students' academic achievement during the learning period affected by COVID-19 in Indonesia. Xia et al., (2013) studied the achievement of peer-to-peer interactions in online discussion forums. Their study documents increased student interaction in online discussion forums at Curtin University. They evaluated the effectiveness of learning initiatives using the online discussion method. Data analysis obtained from Blackboard shows a positive correlation between student learning outcomes and their participation in online discussion forums, as evidenced by some student conversations in the discussion forum. Statistical analysis ensures an objective evaluation of the effectiveness of 
online discussion boards. Promising evidence shows the level of participation in online discussion forums. Thus they have successfully offered the initiative to participate in online discussion forums to create a student community environment that positively enhances student achievement.

Wu et al., (2020) demonstrate a machine learning application to classify text to get the final grade of an advanced hybrid course. They designed three classification models with training data for 77,735 updates from two online discussion forums and applied them to classify messages into statistical and non-statistical related posts in private Facebook groups. Three learning algorithms were compared; effectiveness and conformity of classification with coding. The learning algorithm supports students with more messages because statistics have higher final lesson scores. Their study results indicate that online learning machines, including online discussions, can be applied to identify students' scores who need support in a learning environment through personal social media and control educational data quality.

Findings of Zha and Ottendorfer, (2011) investigated peer leadership's effects on student achievement in online asynchronous discussions. The analysis results revealed that the quality of student leaders' low-level academic achievement in online discussions was significantly better than that of the student respondents. The high-level student achievement, academic success rates in online discussions, is at least the same quality as student respondents. Besides, high and low-level students' academic achievement in discussions has a positive and moderate correlation with the achievement of participants who are not active in online discussion networks.

Cho and Tobias, (2016) said that online discussion is used to increase students' understanding of various topics and promote social interaction among students. They have tested the advantages of online discussion in promoting student learning as measured by the number of communities involved, including student time, social satisfaction, ability tests, and academic achievement. They are learning a significant difference between the cognitive attendance conditions and the instructor's teaching presence, whereas a significant difference was found in the social presence. There is a significant difference between the conditions found for blackboard time, learning satisfaction, and student achievement. The implication is that online discussion teaching and learning and designing online discussion courses much help students achieve each course's goals.

Jacob and Sam, (2008) examines critical thinking in problem-solving discussions of school lessons that are activated through online discussion forums in class in the first year of the lecture supported by a blackboard learning system. The study involved 46 participants in evaluating critical thinking, examining relationships between academic achievement and online critical thinking in online discussion forums, and examine the development of critical thinking skills measured from online discussion forum posts. The trend-based analysis shows an increase in overall learning achievement and the number of online discussion forums. However, the lower phase critical level looks dominant and less dependent on subject achievement and student communication variables through posts and discussions.

Davies and Graff, (2005) study of participant online e-learning performance and student test scores Academic achievement through interacting in online learning programs and discussions has been widely reported. It can be said that online discussions have promoted learning that is centered on student academic achievement. Therefore, it is very appropriate that online discussion benefits should continue to be voiced to increase superior student performance. A study that examined the frequency of online interactions of a hundred students compared them with their marks at the end of the term. The results revealed that online communication in discussions and others resulted in significantly higher performance for students achieving passing grades. However, students who failed their subjects tended to appear less frequently in discussion forums.

Thomas, (2002) examines the pattern of learning interactions with an incoherent structure through distance discussion forum spaces. The results reveal that the typical nonlinear linking structure of virtual or online mode discussions may not be sufficient to realize dedicated conversational learning modes. So this discussion has implications for these findings with 
student learning. So, online discussion forums use new information and communication technology, which are increasingly common in education. It impacts the achievement of student learning outcomes, and their studies become tools to promote online conversational learning modes and are very relevant when linked to the current situation of the pandemic era of distance learning. Therefore it is highly recommended that online discussion forums can improve learning outcomes for students.

Finding Wright and Street, (2016) about a case study of online discussion forums as a way of learning about democracy and deliberation and designing learning is so convincing. In the theory of democracy, variants of consideration have become the primary way to improve learning outcomes. This approach represents the ideals of learning democracy through online discussion forums. It has been recommended as a solution to the practical limitations of mass deliberation. Critics have pointed to evidence showing that online discussion tends to undermine judgment. This article argues that this claim, which results in a clash between the two camps, misses one major problem: designing plays in facilitating or thwarting deliberation. He argued that political choices were made both about online discussions' format and operation, which influenced the likelihood of deliberation.

Pendry and Salvatore, (2015) findings have sparked debate around the potential benefits of online conversation discussions and interactions. Their research reveals that engagement with online discussion forums can have less appreciative benefits for users' welfare and engagement in offline learning actions. Findings with other online forum users play an essential role in this, especially when it comes to learning outcomes. Online users of various online discussion forums participated in this research session and found an extensive online discussion role. They analyzed and found that participants who took part in online discussions had higher scores than those who were not interested in online story modeling. Likewise, they estimated outcome satisfaction by scoring high compared to engagement in offline discussion activities. The main findings confirm that the effort serves as a mediator for both of these academic outcomes. Whether the discussion forum concerns the stigmatized topic being discussed is sure that this reciprocal relationship is an outcome explained in practical and applied implications for the new learning method.

Carceller et al., (2013) proved that academic achievement improved through participating in online discussion forums. 132. Their findings reported a potential relationship between student discussion forum activity and academic achievement. This academic achievement, data from forum discussion participation and teaching methods were extracted from the university's face-to-face learning system. The findings identified that those students who were very active in online discussion forums were more likely to achieve higher final grades than those who only learned the conventional way. This researcher also observed that the effect resulting from participating in discussions in online teaching forums was more significant in learning motivation. Their conclusion confirms that the learning analytics data from online discussion forums are relevant to be applied proactively to improve teaching and learning practices, especially the anticipation of distance learning as long as schools are not yet reopening.

This discussion section summarizes online discussion studies' conclusions to improve academic achievement results in the Indonesian learning context. Based on the evidence from ten scientific publication journals about the effectiveness of online discussion applications, we can say that this finding is very revealing with the questions of this study, especially when Indonesia is still implementing a policy of learning from home or learning from a remote place. We believe that every pepper we review, all are the same in their conclusion that all their points emphasize the principle of utility and the relevance of activeness and academic achievement results. On average, it is revealed that the more active in online discussion learning media, the more promising the results of student academic achievement. For example, they are reviewed by Klisc et al., (2009), which supports our findings with their study of the effect of assessment on the outcomes of asynchronous online discussion as perceived by instructors. Their studies were conducted in Australia in terms of technology and educational success. If we look closely at the average adoption of methods in developed countries, it plays an essential role in implementing technology in education, especially in higher education. 
The following points are useful for discussing efforts to increase student academic achievement during a pandemic through an online learning approach, especially the online discussion method. For such activities to be successful, there are essential aspects that must be considered, for example, the availability of online learning infrastructure. Without the availability of this facility, it would not be possible to run. It can be understood that Indonesia's current real condition is not yet able to provide high-tech infrastructure so that even new findings cannot be fully implemented. Whatever the reasons, this infrastructure is indeed the main prerequisite for adequate and widespread distance learning for all Indonesian citizens in the pandemic era and other world citizens. For example, research by Hornik and Cagle, (2005) states that technology-assisted teaching requires infrastructure support so that online discussions can take place. Technology is no longer a foreign trend in education but has become a standard item in daily life, even in underdeveloped countries.

Another point that should receive special attention is the digital skills of educators. This problem is very problematic for the Indonesian context, where it is often found that many educators and students are equally problematic with the latest technology application skills. According to technology-based learning experts, digital skills for both teachers and students are an essential factor. It must be understood that it is often the digital divide in the digital era. For example, the gap between the older generation's digital skills or the immigration of generations and students as the native digital generation is a serious problem. Competence and literacy in using computers and surfing in cyberspace are essential skills needed not only in the educational environment but in other careers. Dixson et al., (2006) also thought about creating practical online discussions and learning about instructors and student roles' roles and skills. So if both of their roles are effective, then technology-based learning models such as online discussions can occur.

The contribution of this study show that online discussions can improve student learning outcomes research, allows students to collaborate with various experts and scientists in the field. The more experts involved in the collaboration, the higher the chance to get the experience of various kinds of science. The researcher developed this online discussion study with efforts by academics and researchers to find solutions to various learning problems during COVID-19 learning time. This time has hindered students from learning. Thus, the science of teaching develop not only in difficult times due to the pandemic but also in the future, how online discussion to be a solution and a controversy for learning in Indonesia, especially in areas where so far only learn manually. In the distance learning process, online discussion boards can be applied as a medium for student learning stimuli to foster interest in learning, motivation, and student enthusiasm regarding trending topic issues in a particular topic lesson. It is hoped that an online class discussion board can reduce students' feeling overwhelmed by the conventional learning process in the classroom and encourage better performance in other communicative contexts, especially the achievement of student academic outcomes at every level of education. By using a scientific study mind and a reflective mind, educators feel they can solve all the problems that arise in their way. The uncertainties in adopting technology and the availability of various applications that can be used in distance learning models, such as WhatsApp, Google Meet, Zoom, and Line, have created new challenges, especially for teachers. Because each application has unique characteristics that affect students' and lecturers' interaction, it is essential to consider. The main concern is that these applications' impact on the quality of learning outcomes is a concern of every policymaker in education. Azevedo et al., (2020), for example, an application like Zoom, which has more prosperous and more interactive features, give better results than the WhatsApp medium. Teachers must understand the characteristics of the technology used in online learning, especially related to knowledge of the advantages and disadvantages of the applications used to learn projects during the pandemic that can be carried out optimally.

\section{CONCLUSION}

This research reported that online discussion boars as an alternative technique to improve academic outcomes during the pandemic era, noting that the ten international publications we 
reviewed have answered the questions and objectives of this study. The critical points include the importance of technology adoption and new application ideas along with the advancement of the technological era applied in the learning context, especially online discussion boards and exceptional attention to the availability of technological infrastructure and the role and skills of using a variety of applications that can be used to turn on distance learning during the pandemic, connecting learning and saving students' lives. The application of online discussion, which most experts consider a significant advantage of online platform-based learning, is essential. It includes improving long-distance communication among learning communities, increasing collaboration among one discipline and study program, the learning community's involvement in modern learning methods, and encouraging the use of Massive online collaboration discussions in the era of technology even though it is still affected by COVID-19. From the description above, we can conclude that this study's findings have answered this study's questions with actual evidence from the ten publications we studied as credible and valid data sources.

\section{ACKNOWLEDGEMENT}

The author expressed his sincere gratitude to the officials and publisher. This research was funded by the Budget Allocation of Sekolah Tinggi Ilmu Ekonomi Balikpapan the fiscal year of 2020. This research was categorized into Individual Research. Thank you also expressed to the researchers who has contribute their thought, time and energy to help finish. Thank grateful to all parties who have contributed to the writing of this paper entitled, "review of online discussion board to improve academic achievement in pandemic time learning". For your help and support, we really appreciate it. Especially our faculty and colleagues for all input and criticism

\section{AUTHOR CONTRIBUTION STATEMENT}

As a single author, it was very grateful to contribute to this paper from the initiation of the problem to the drafting process with the support of the professional editor for the content and writing part. Sudarmono designed research, collects the data, conduct analysis, and finishing process peer review.

\section{REFERENCES}

Azevedo, De, J.P.W., Hasan, Amer, Goldemberg, Diana, Iqbal, Aroob, S., Geven, Martijn, K., 2020. Simulating the Potential Impacts of COVID-19 School Closures on Schooling and Learning Outcomes: A Set of Global Estimates (English). World Bank 1. https://doi.org/10.1596/1813-9450-9284

Caffarella, R.S., Daffron, S.R., 2013. Planning programs for adult learners: A practical guide. John Wiley \& Sons. Google Scholar

Carceller, C., Dawson, S., Lockyer, L., 2013. Improving academic outcomes: does participating in online discussion forums payoff? Int. J. Technol. Enhanc. Learn. 5, 117-132. https://doi.org/10.1504/IJTEL.2013.059087

Cheng, C.K., Paré, D.E., Collimore, L.-M., Joordens, S., 2011. Assessing the effectiveness of a voluntary online discussion forum on improving students' course performance. Comput. Educ. 56, 253-261. https://doi.org/10.1016/j.compedu.2010.07.024

Cho, M.-H., Tobias, S., 2016. Should instructors require discussion in online courses? Effects of online discussion on community of inquiry, learner time, satisfaction, and achievement. Int. Rev. Res. Open Distrib. Learn. 17, 123-140. https://doi.org/10.19173/irrodl.v17i2.2342

Coetzee, D., Fox, A., Hearst, M.A., Hartmann, B., 2014. Should your MOOC forum use a reputation system?, in: Proceedings of the 17th ACM Conference on Computer Supported Cooperative Work \& Social Computing, CSCW '14. Association for Computing Machinery, New York, NY, USA, pp. 1176-1187. https://doi.org/10.1145/2531602.2531657 
Crawford, J., Butler-Henderson, K., Jurgen, R., Malkawi, B.H., Glowatz, M., Burton, R., Magni, P., Lam, S., 2020. COVID-19: 20 countries' higher education intra-period digital pedagogy responses. J. Appl. Learn. Teach. 3. https://doi.org/10.37074/jalt.2020.3.1.7

Daloz, L.A., 2012. Mentor: Guiding the journey of adult learners (with new foreword, introduction, and afterword). John Wiley \& Sons. Google Scholar

Davies, J., Graff, M., 2005. Performance in e-learning: online participation and student grades. Br. J. Educ. Technol. 36, 657-663. https://doi.org/10.1111/j.1467-8535.2005.00542.x

Dixson, M., Kuhlhorst, M., Reiff, A., 2006. Creating effective online discussions: Instructor and student roles. J Asynchron Learn Netw. Google Scholar

Fauzi, I., \& Khusuma, I. H. S. (2020). Teachers' Elementary School in Online Learning of COVID-19 Pandemic Conditions. Jurnal Iqra': Kajian Ilmu Pendidikan, 5(1), 58-70. https://doi.org/10.25217/ji.v5i1.914

Hornik, S., Cagle, J.A., 2005. Teaching with technology: Infrastructure support and online discussions. Integrating Technol. High. Educ. 1-17. Google Scholar

Ilyasa, F., Rahmayanti, H., Muzani, M., Ichsan, I. Z., \& Suhono, S. (2020). Environmental Education for Prevent Disaster: A Survey of Students Knowledge in Beginning New Normal of COVID-19. International Journal on Advanced Science, Education, and Religion, 3(2), 1-8. https://doi.org/10.33648/ijoaser.v3i2.60

Jacob, S.M., Sam, H.K., 2008. Critical thinking skills in online mathematics discussion forums and mathematical achievement, in: Proceedings of the 13th Asian Technology Conference in Mathematics (ATCM 2008), Thailand. pp. 15-19. Google Scholar

Jones, D.C., Abbey, B.B., Cumberland, A., 1998. The development of display rule knowledge: Linkages with family expressiveness and social competence. Child Dev. 69, 12091222.

Klisc, C., McGill, T., Hobbs, V., 2009. The effect of assessment on the outcomes of asynchronous online discussion as perceived by instructors. Australas. J. Educ. Technol. 25. https://doi.org/10.14742/ajet.1114

Lassoued, Z., Alhendawi, M., Bashitialshaaer, R., 2020. An Exploratory Study of the Obstacles for Achieving Quality in Distance Learning during the COVID-19 Pandemic. Educ. Sci. 10, 232. https://doi.org/10.3390/educsci10090232

Machado, R.A., Bonan, P.R.F., Perez, D.E. da C., Martelli JÚnior, H., 2020. COVID-19 pandemic and the impact on dental education: discussing current and future perspectives. Braz. Oral Res. 34. Google Scholar

McMillan, J.H., Schumacher, S., 2010. Research in Education: Evidence-Based Inquiry, MyEducationLab Series. Pearson. Google Scholar

Palloff, R.M., Pratt, K., 2007. Building online learning communities: Effective strategies for the virtual classroom. John Wiley \& Sons. Google Scholar

Pendry, L.F., Salvatore, J., 2015. Individual and social benefits of online discussion forums. Comput. Hum. Behav. 50, 211-220. https://doi.org/10.1016/j.chb.2015.03.067

Putra, P., Liriwati, F. Y., Tahrim, T., Syafrudin, S., \& Aslan, A. (2020). The Students Learning from Home Experiences during Covid-19 School Closures Policy In Indonesia. Jurnal Iqra': Kajian Ilmu Pendidikan, 5(2), 30-42.. https://doi.org/10.25217/ji.v5i2.1019

Romero, C., López, M.-I., Luna, J.-M., Ventura, S., 2013. Predicting students' final performance from participation in on-line discussion forums. Comput. Educ. 68, 458472.

Smith, J.A., Osborn, M., 2020. Interpretative Phenomenological Analysis. Qual. Psychol. 28. Google Scholar

Surani, D., \& Hamidah, H. (2020). Students Perceptions in Online Class Learning During the Covid-19 Pandemic. International Journal on Advanced Science, Education, and Religion, 3(3), 83-95. https://doi.org/10.33648/ijoaser.v3i3.78

Thomas, M.J., 2002. Learning within incoherent structures: The space of online discussion forums. J. Comput. Assist. Learn. 18, 351-366. 
Wright, S., Street, J., 2016. Democracy, deliberation and design: the case of online discussion forums: New Media Soc. https://doi.org/10.1177/1461444807081230

Wu, J.-Y., Hsiao, Y.-C., Nian, M.-W., 2020. Using supervised machine learning on large-scale online forums to classify course-related Facebook messages in predicting learning achievement within the personal learning environment. Interact. Learn. Environ. 28, 65-80. https://doi.org/10.1080/10494820.2018.1515085

Xia, J.C., Fielder, J., Siragusa, L., 2013. Achieving better peer interaction in online discussion forums: A reflective practitioner case study. Issues Educ. Res. 23, 97-113. Google Scholar

Zha, S., Ottendorfer, C.L., 2011. Effects of peer-led online asynchronous discussion on undergraduate students' cognitive achievement. Am. J. Distance Educ. 25, 238-253. https://doi.org/10.1080/08923647.2011.618314

Copyright Holder :

(C) Sudarmo, (2020).

First Publication Right :

(C) Tapis : Jurnal Penelitian Ilmiah

This article is under:

CC BY SA 